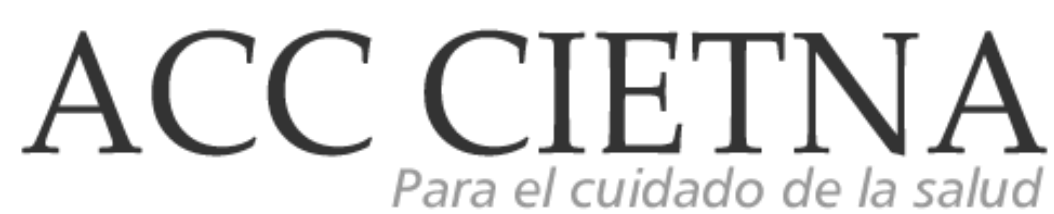

https://doi.org/10.35383/cietna.v8i1 1.575

ARTÍCULOS DE INVESTIGACIÓN ORIGINALES

\title{
Nivel de conocimiento y práctica preventiva en la población afectada con dengue, Ferreñafe, 2019
}

\author{
Bravo Rodríguez Pamela del Carmen', Zapata Rueda Aurora Violeta²
}

\section{INFORMACIÓN DEL}

ARTÍ́CULO

\section{Historia del artículo:}

Recibido el 09 de abril de 2021

Aceptado el 07 de julio de 2021

\section{Palabras clave:}

Dengue (D003715)

Conocimiento (D019359)

Prevención de enfermedades

(50219)

\section{RESUMEN}

Objetivo: Identificar la relación que existe entre el nivel de conocimiento y la práctica preventiva en personas afectadas con dengue, Ferreñafe 2019. Método: Estudio cuantitativo con diseño descriptivo correlacional. La muestra estuvo conformada por 252 personas afectadas con el virus del dengue, el muestreo fue por conveniencia teniendo en cuenta los criterios de inclusión y exclusión. Se utilizó como técnica la encuesta y como instrumento un cuestionario para medir el nivel de conocimiento y una lista de chequeo para la práctica preventiva elaborado por García, Torres y Tangoa, se validaron los instrumentos a nivel local con el método de Kuder de Richardson teniendo 0.890 y 0.820 de confiabilidad respectivamente. Resultados principales: Sí existe una relación positiva perfecta y directamente proporcional relación con significancia bilateral $(r s=0.858, p=0.000)$ entre nivel de conocimiento y práctica preventiva en la población afectada con dengue. Por lo que se rechaza la hipótesis nula.

\section{Nurse's experience in the face of pediatric patient death}

\section{ABSTRACT}

\section{Keywords:}

Dengue (D003715)

Knowledge (D019359)

Disease prevention (50219)
Objective: Identify the relationship between the level of knowledge and preventive practice in people affected with dengue, Ferreñafe 2019. Method: Quantitative study with descriptive correlational design. The sample consisted of 252 people affected with the dengue virus, the sampling was for convenience, taking into account the inclusion and exclusion criteria. The survey was used as a technique and as a tool a

'Enfermera asistencial en el Centro de Salud de Pópame, Monsefú, Lambayeque, Perú. Licenciada en Enfermería de la Escuela de Enfermería de la Universidad Católica Santo Toribio de Mogrovejo, Chiclayo, Perú. Email: bravop632@gmail.com. ORCID: https://orcid.org/0000-0001-5723-1713

2Magister en Ciencias de Enfermería. Docente de la Universidad Católica Santo Toribio de Mogrovejo, Chiclayo, Perú. Email: azapata@usat.edu.pe ORCID: https://orcid.org/0000-0003-0642-3277 
questionnaire to measure the level of knowledge and a checklist for preventive practice prepared by García, Torres and Tangoa, instruments were validated at the local level with the Richardson's Kuder method having 0.890 and 0.820 reliability respectively. Main results: Yes, there is a perfect and directly proportional positive relationship with bilateral significance ( $r s=0.858, p=0.000$ ) between the level of knowledge and preventive practice in the dengue-affected population. So, the null hypothesis is rejected. General conclusion: The higher the level of knowledge presented by the person affected by dengue, the preventive practice that is developed is very good or vice versa.

\section{Introducción}

El dengue es un arduo problema de salud pública a nivel mundial, siendo una enfermedad muy incierta en la actualidad. Velayudhan ${ }^{1}$ describió al dengue como una patología dinámica al mismo tiempo, desapercibida; siendo la principal conminación debido al cambio climático y ambiental, lo que provee la habituación de los vectores (Aedes aegypti y albopictus), el poder eliminarlos refiere es un evento prácticamente difícil sin embargo pone hincapié en la necesidad de concientizar a la población a través de la educación y señala que la OMS ha estado laborando en una serie de implementos y tecnologías para contribuir a varios países en el control de vectores, lo que es posible lograr a través de la educación.

La incidencia del virus en Latinoamérica se da debido a la capacidad de aclimatación del Aedes aegypti por lo que se tiene una circulación parecida de los tres arbovirus (dengue, zika y chikungunya), para ello es indispensable tener en cuenta los factores que ayudan a la transmisión de los arbovirus, puede dar a inferir lo difícil que es llevar a cabo el control de vectores de una manera más eficaz, a esto se le suma la importancia de englobar que cuestiones como el saneamiento básico inadecuado, el crecimiento urbano desordenado, la población en las ciudades, las desviaciones en el suministro de agua y los residuos domésticos, son responsables del $80 \%$ de los focos de mosquitos; necesitándose así varias medidas para combatir el dengue ${ }^{2}$.
En el Perú, los departamentos que presentan condiciones climatológicas favorables para el desenvolvimiento vital del vector son: Ucayali, Amazonas, Loreto y Tumbes, manteniéndose esto durante los últimos 10 años reflejados en las semanas epidemiológicas presentadas por el MINSA ${ }^{3}$.

En Ferreñafe, para el día 04 de junio del año 2019 según fuente del Puesto de Salud Señor de la Justicia se reportaron 252 casos, siendo el último caso reportado el día antes mencionado.

De allí que la investigadora planteó la siguiente interrogante de investigación: ¿Cuál es la relación entre el Nivel de conocimiento y la Práctica preventiva en personas afectadas con dengue en la Unidad vecinal Señor de la Justicia, Ferreñafe 2019 ?

El objetivo general fue determinar la relación que existe entre el Nivel de conocimiento y la práctica preventiva en personas afectadas con dengue, Ferreñafe 2019. Así mismo los objetivos específicos fueron: determinar el nivel de conocimiento en las personas afectadas con dengue y determinar la práctica preventiva en personas afectadas con dengue, Ferreñafe 2019.

\section{Metodología}

Esta investigación fue cuantitativa, no experimental, diseño descriptivo, correlacional de corte trasversal ${ }^{4}$. 
La población estuvo conformada por las personas afectadas con el virus del dengue en la Unidad vecinal Señor de la Justicia, Ferreñafe hasta el mes de Mayo del 2019, referente a 252 casos. La muestra fue determinada mediante el software Launch Stats $2.0^{5}$ obteniendo así 152 personas. El muestreo fue por conveniencia, de acuerdo con la lista proporcionada por la encargada de la Estrategia de metaxénicas. Se incluyó a personas que hayan padecido del virus del dengue, personas de ambos sexos, que residan en el distrito de Ferreñafe; y se excluyó a personas que no hablen idioma castellano y con alteraciones mentales.

Para la recolección de datos, se utilizó como técnica la encuesta, como instrumento para recolectar los datos se utilizaron el Cuestionario titulado Conocimiento sobre el dengue que consta de 20 preguntas sobre conocimiento del virus, también se utilizó una lista de chequeo que consta de 20 ítems para identificar las principales prácticas preventivas frente al dengue. Se evaluó con el siguiente puntaje: Conocimiento adecuado: 20 - 40, Conocimiento inadecuado: menos de 20. Prácticas para prevenir el dengue: Sí práctica medidas preventivas: $13-20$, No práctica medidas preventivas: $<13$

La validación del instrumento se hizo a través de una prueba piloto, realizada en el distrito de Tumán, donde tiene una población con características similares a la señalada para el desarrollo de esta investigación, la prueba se realizó con un mínimo de 30 personas, luego se aplicó el estadístico Kuder Richardson 6 dando como resultado 0.890 y 0.820 de confiabilidad cada instrumento respectivamente.

Al mismo tiempo, se procedió a aplicar los instrumentos de acuerdo con la muestra señalada, programando visitas domiciliarias a través de llamadas realizándose cronograma con fechas y horas exactas, realizando 7 visitas por día, para la ejecución se necesitó la ayuda de un encuestador el cual antes de empezar la ejecución fue capacitado, considerando para ello la revisión en conjunto del proyecto, así como un taller sobre como ejecutar los instrumentos fue de $15-30$ minutos por cada persona

Con los datos adquiridos de las encuestas, se construyó una base de datos en Microsoft Excel, se guardó en una carpeta para su procesamiento y se procedió con el traslado al programa SPSS para iniciar con la realización de los gráficos correspondientes de cada instrumento y sus ítems respectivos, finalmente la Correlación de Spearman ${ }^{7}$, nos ayudó a obtener la relación que existe entre las variables. Así mismo para poder responder los objetivos específicos, se realizó la sumatoria de puntajes de ambos instrumentos, se procedió a su clasificación respectiva, según la escala de medida obteniéndose finalmente la frecuencia y porcentaje.

Los criterios que se utilizaron en esta investigación estuvieron fundados en los principios de ética personal según Sgreccia $^{8}$, los cuales se tomó en cuenta el principio de defensa a la vida física en donde los participantes fueron tratados de una manera integral, con mucho respeto; como un ser digno y racional, teniéndose en consideración las respuestas de los cuestionarios, siendo las encuestas de manera anónima, por ello fueron codificadas protegiendo siempre la identidad de la persona.

Al mismo tiempo se tuvo presente el principio de libertad y responsabilidad de la persona, donde tuvieron la capacidad de decidir libre y voluntariamente su participación, conocieron la hoja informativa y a la investigadora, asumiéndose toda la responsabilidad de no exponer la identidad de la persona y la información obtenida. Finalmente se consideró el principio de sociabilidad y subsidiaridad, donde esto fue puesto en práctica en el proceso de toda la investigación, estuvo basada en el bien común de la persona, buscando resultados para así poder lograr una buena calidad de vida. Se obtuvo la Resolución de aprobación del proyecto de investigación con N $N^{0} 503$ - 2019 - USAT - FMED posterior a ello, se obtuvo la autorización de GERESA, para proceder a la ejecución del proyecto, 
solicitando el listado de casos reportados de dengue hasta el mes de junio del 2019.

\section{Resultados}

\section{Tabla $\mathbf{N}^{\circ} 01$}

Correlación entre Nivel de Conocimiento y Práctica preventiva en la población afectada con dengue, Señor de la Justicia 2019

\begin{tabular}{ccc}
\multicolumn{2}{c}{ Rho de Spearman } & $\begin{array}{c}\text { Nivel de } \\
\text { conocimiento }\end{array}$ \\
\hline Práctica & Coeficiente de &, $858^{* *}$ \\
preventiva & correlación &, 000 \\
\multicolumn{2}{c}{ Sig. } & 152 \\
\hline ** La correlación es significativa al nivel 0,01 \\
(bilateral).
\end{tabular}

Fuente: Realización particular

\section{Interpretación:}

Se deduce que, entre el nivel de conocimiento y práctica preventiva del sujeto de estudio, el nivel de significancia $(p=0.000)$ es menor a 0.05 , por lo que se rechaza la $\mathrm{HO}$, entonces existe una relación lineal entre estas variables. Además, la correlación es muy buena y directamente proporcional (rho Spearman $=0.858$ ), es decir que a mayor rango de nivel de conocimiento que presente el individuo, la práctica preventiva que desarrolle es muy buena o viceversa.

\section{Tabla $\mathbf{N}^{\circ} 2$}

Nivel de conocimiento en la población afectada con dengue, Señor de la Justicia 2019

Frecuencia Porcentaje

\begin{tabular}{ccc}
\hline \hline $\begin{array}{c}\text { Conocimiento } \\
\text { Inadecuado } \\
\begin{array}{c}\text { Conocimiento } \\
\text { adecuado }\end{array}\end{array}$ & 7 & $4,6 \%$ \\
\hline Total & 152 & $95,4 \%$ \\
& Fuente: Realización particular
\end{tabular}

Universidad Católica Santo Toribio de Mogrovejo - Chiclayo, Perú

\section{Interpretación:}

Se deduce que el $95,39 \%$ de las personas que habitan en la unidad vecinal, presentan un adecuado conocimiento sobre el dengue y el porcentaje restante $4,61 \%$ tiene un conocimiento inadecuado sobre el virus en estudio.

\section{Tabla $N^{\circ} 3$}

Práctica preventiva en la población afectada con dengue, Señor de la Justicia 2019

\begin{tabular}{ccc} 
Indicador & Frecuencia & Porcentaje \\
\hline \hline $\begin{array}{c}\text { No práctica } \\
\text { medidas } \\
\text { preventivas }\end{array}$ & 16 & $10,5 \%$ \\
$\begin{array}{c}\text { Sí práctica } \\
\text { medidas } \\
\text { preventivas }\end{array}$ & 136 & $89,5 \%$ \\
\hline \hline Total & 152 & 100,0 \\
& Fuente: Realización particular
\end{tabular}

Interpretación:

Se deduce que el $89,47 \%$ de las personas que habita en la unidad vecinal, si práctica medidas preventivas ante el dengue y el porcentaje restante $10,53 \%$ no practica medidas preventivas ante el virus en estudio.

\section{Discusión}

En cuanto a la relación que existe entre nivel de conocimiento y práctica preventiva en personas afectadas con dengue, según Spearman ${ }^{7}$, se encontró una relación positiva perfecta y directamente proporcional dando como resultado rho Spearman: 0.858 , es decir que a mayor conocimiento que tenga la persona, la práctica preventiva que desarrolla es la correcta y viceversa; teniendo así una significancia bilateral ${ }^{4,9}$

Entonces, para la presente investigación queda rechazada la hipótesis nula (HO), puesto que en la actualidad los sujetos de estudio presentan un conocimiento adecuado y la práctica preventiva de 
igual manera. Se deduce que ambas acciones se mejoraron a raíz de la mala experiencia que pasaron al enfermarse de este virus que afectó a cientos de personas residentes en la unidad vecinal y el proceso de hospitalización tomando conciencia sobre la importancia que tienen las actividades propuestas por el establecimiento de salud, también porque al pasar por el proceso de la enfermedad las personas se vieron obligadas al mismo tiempo es posible afirmar que la aceptación de las intervenciones realizadas por el centro de salud, para el control de este virus han favorecido a un reforzamiento al nivel de conocimiento y por lo tanto una mejora de la práctica, además es posible evidenciar que las personas ya no muestran una conducta de indiferencia a ciertas actividades como por ejemplo la abatización, fumigación, recojo de inservibles y la verificación del almacenamiento del agua, etc.

Al contrastar con otros resultados, Campos y Corcino $^{10}$, obtuvieron como resultado según Chi cuadrado: 0.004 , es decir acepta la hipótesis alterna, donde refiere que si existe relación entre el nivel de conocimiento y las prácticas en la prevención y control del virus del dengue, que concuerda con la relación encontrada entre las variables en esta investigación, cabe mencionar que en las poblaciones de ambos estudios, se encontraron debilidades como por ejemplo las actividades programadas por el personal de salud para la eliminación de basura o inservibles y campañas de abatización.

En relación al objetivo específico número uno: determinar el nivel de conocimiento en las personas afectadas con dengue; se tiene que el 95.39\% de las personas que habitan en dicha unidad vecinal presentan un adecuado conocimiento, y el porcentaje restante $4.61 \%$, tiene un conocimiento inadecuado sobre el virus en estudio; estos resultados son semejantes a los encontrados por Núñez ${ }^{11}$, donde refiere que el conocimiento clasificado en muy bajo, bajo, regular, alto y muy alto con porcentajes $(0 \%, 7 \%$, $21 \%, 44 \%$ y $28 \%$ ) respectivamente.
Al mismo tiempo, los resultados presentados por Juárez ${ }^{12}$, quien clasificó al conocimiento en alto, medio y bajo teniendo como resultados $30 \%$, $52 \%$ y $18 \%$ respectivamente, por lo tanto, esta investigación no coincide con los resultados encontrados.

En esta presente investigación se clasificó a los sujetos de estudio según las etapas de vida determinadas por el MINSA ${ }^{13}$, jóvenes (18 - 29 años), adultos (30 - 59 años) y adultos mayores de (60 años a más), teniendo así que la mayoría de los sujetos de estudios son adultos correspondientes a 85 personas de ambos sexos con un grado de instrucción de secundaria completa; coincidiendo con los datos del Instituto Nacional de Estadística e Informática (INEI) ${ }^{14}$, donde hace evidencia que en Perú el grado de instrucción para el año 2018 con más porcentaje es de secundaria completa, por lo que esto justifica que el nivel de conocimiento sea el adecuado en estas personas, teniendo una educación base para el proceso de aprendizaje y comprensión de lo enseñado por el personal de salud.

Para Amador, Monreal y Marco'5; la adultez es la etapa donde se da el pleno desarrollo en la capacidad de aprendizaje basados en las experiencias brindadas de generación en generación, esto ayudará a cada persona a contextualizar también nuevos conocimientos favoreciendo a la comprensión de estos.

Estos resultados coinciden con Jiménez ${ }^{16}$, que nos hace referencia que en esta etapa de vida se da la continuidad al desarrollo normal en el ciclo vital de la persona, otorgándole sentido y aprendizaje para vivir en plenitud, con la finalidad de tener el bienestar en todo el sentido sea físico o psicológico.

Por otro lado, en lo que respecta al segundo objetivo específico: determinar la práctica preventiva en personas afectadas con dengue en la unidad vecinal Señor de la justicia - Ferreñafe 2019; en esta investigación se obtuvo como resultados que el $89.5 \%$ de las personas 
encuestadas si practican medidas preventivas y el porcentaje restante no lo realiza. Evidenciándose que estos resultados no coinciden con la investigación realizada por Rodrìguez ${ }^{17}$, encontrándose que la práctica preventiva que tuvieron estos sujetos de estudio fue de manera regular no coincidiendo con esta investigación y finalmente con un $10 \%$ su práctica fue deficientes y bueno respectivamente.

A su vez Juárez ${ }^{18}$, en su investigación, clasifica también a la práctica en tres niveles alto, medio y bajo encontrando como resultados 18, 46 y $36 \%$ respectivamente, no coincidiendo así con los resultados encontrados en esta investigación, por lo que se encontraron falencias en la forma de conservación de agua, eliminación de inservibles y en la manera de protección de que tienen, difiriendo esto con la población estudiada donde su práctica preventiva es adecuada.

Comparando también con la investigación hecha por Quispe y Zevallos'19, clasifican el nivel de prácticas en buenas, regulares y deficientes con un porcentaje de $(16.92 \%, 36.92 \%$ y $46.15 \%)$ respectivamente, no coinciden con los resultados encontrados puesto que los sujetos de estudio presentan buenas prácticas preventivas en la actualidad.

En la realidad, se hace evidente que son los sujetos de sexo femenino las que practican medidas preventivas en un mayor porcentaje, sumándole a ello que la etapa con mayor porcentaje de prácticas son los adultos. Esto coincide con la investigación realizada por Jiménez y Moya ${ }^{20}$, donde nos refiere que el hecho del cuidar por parte de la mujer no es una decisión impuesta, puesto que por lo general la asume con total naturalidad y con mucha lógica; al mismo tiempo la sociedad considera un cambio poco natural y habitual que el varón asuma la responsabilidad del cuidado frente a un hogar.

También para Massé21, la mujer ejerce un papel fundamental e importante para el cuidado del hogar, por lo que posee valores muy significativos a diferencia de los varones, coincidiendo también en que el cuidar para la mujer es un ámbito por naturaleza, relacionado con la moral viéndolo así como la obligación de velar por los demás, a esto se le suma que existen valores femeninos agregados dentro de ellos el sacrificio y la entrega, expresándose por una calidez emocional, acompañado del instinto maternal que se posee.

Los resultados anteriormente presentados, difieren con Hernández y Guillen ${ }^{27}$, puesto que estos autores nos refieren que en los últimos años se ha reflejado cambios en la dinámica familiar, como por ejemplo la distribución de funciones laborales y domesticas en ambos sexos, siendo así que en el género masculino hoy en día también asume los roles domésticos como, por ejemplo: el cuidado de los hijos, actividades diarias del hogar, etc.

Hoy en día, tenemos como gran referente a nivel mundial al feminismo siendo este un movimiento social y político que tiene como principal objetivo la restructuración domestico - familiar y la paridad económica - laboral; siendo ello el pilar principal hoy en día para la igualdad de género, viéndose reflejado en la actualidad en la distribución de roles domésticos, laborales entre hombres y mujeres; las cuales desde hace varias décadas luchan por la igualdad de derechos y que sea reconocidas como tal28.

A diferencia de otro tiempo por referencias del personal que se desempeña en el centro de salud de dicha unidad vecinal, cuando el virus empezó a propagarse se programaron actividades como: Educación a la población a través de charlas educativas semana a semana, seguimiento en los domicilios de los moradores para la respectiva abatización y al mismo tiempo la verificación del proceso de almacenamiento de agua y el estado de sus depósitos; sin embargo, refieren los encargados de las actividades, que algunos de los pobladores rechazaban la abatización y fumigación por temor a que las sustancias empleadas pudieran causar daño a su salud, ya que consideraban que los productos podrían contaminar sus alimentos por ejemplo el agua que 
almacenaban para su uso diario, etc., cabe mencionar que esta población posee algunas creencias culturales muy arraigadas lo que les lleva a realizar prácticas culturales que les permiten dicen ellos prevenir o eliminar el mosquito causante de esta enfermedad, inclinándose por la quema del eucalipto, palo santo, a pesar de conocer cómo hacer frente a estos mosquitos. Contrastando lo antes mencionado con Niño y Yong 22 , coinciden con los resultados de su investigación, porque los conocimientos y prácticas sobre dengue, fueron insuficientes $y$ escasos en su población estudiada, conllevando a un brote desenfrenado del virus al igual que en la Provincia de Ferreñafe.

Cabe también mencionar en este apartado que para Kozier ${ }^{23}$ y Köhler ${ }^{24}$, nos definen a la percepción como la simbolización cognitiva $y$ psicológica, que influye directamente en las emociones de la persona frente a una patología y su actitud frente a ello, observándose cambios conductuales como por ejemplo en la rutina de su vida diaria, cuidados específicos para la prevención y recuperación ya que siempre va a volver a enfermar. Por lo tanto, relacionando los datos con Kozier, Köhler, las personas estudiadas en esta investigación presentan una percepción inadecuada de este virus considerándola no grave y afrontándola con conducta de indiferencia, por lo que su comportamiento frente a esta situación no era la correcta siendo así un factor importante para el aumento de casos en esta población.

Resulta importante conocer que en los alrededores de las diferentes unidades vecinales de esta provincia se cultiva arroz, caña de azúcar, etc., siendo estas, siembras que requieren de riegos constantes, por lo que sus tierras permanecen húmedas y con aguas estancadas sumándole a ello la temporada de lluvias en nuestra región, lo que constituye un factor que favorece la reproducción de este vector. Esta información antes presentada, concuerda con lo descrito en la Guía de práctica clínica para la atención de casos de dengue en el Perú 6 , donde en los factores de riesgos asociados se tiene como principal, al medio ambiente, en este apartado nos describe que el clima tropical asociado a elevadas temperaturas, temporada de lluvia y humedad, va a favorecer al ciclo biológico del vector, al simplificar el número de días necesarios para que el huevo se convierta en adulto.

También es necesario mantenerse en alerta dadas las condiciones mencionadas, al mismo tiempo según la información brindada por la Estrategia de metaxénicas, dentro de las personas afectadas, se encuentran casos de personas reincidentes a esta enfermedad, por lo cual están expuestos a mayores riesgos o consecuencias, en relación a la primera infección que tuvieron incluida la posibilidad de contraer, dengue grave que es morta|6,25,26. Vale mencionar que dentro de los sujetos de estudio se encuentran adultos mayores, lo cual son especialmente susceptibles a la deshidratación por la fase febril de este virus, y muchos de ellos por sus creencias o costumbres, son renuentes a solicitar atención médica temprana y su primera opción es la medicina tradicional, esto concuerda con lo referido por el personal de salud encargado, también siendo el escenario antes descrito el principal factor de riesgo que conllevaría a la proliferación de Aedes aegypti en esta ciudad, por lo que los casos confirmados iban en aumento 26 .

La investigadora, puede recalcar que tanto el nivel de conocimiento y práctica preventiva que hoy en día presentan las personas que fueron afectadas por el virus del dengue ha ido mejorando con el pasar de los meses, teniendo ello una relación con el proceso de hospitalización que vivieron el que fue una experiencia desagradable, pero les ha permitido tomar conciencia sobre la importancia que tienen las actividades propuestas por el establecimiento de salud; al mismo tiempo estos resultados son muy importantes para los profesionales de salud, porque son ellos los encargados de establecer las medidas y estrategias para educar y sensibilizar a la población. 
Limitaciones: No se presentó ninguna limitación en el desarrollo y ejecución del estudio.

\section{Conclusiones}

Existe una relación positiva perfecta y directamente proporcional, entre el nivel de conocimiento y práctica preventiva, es decir que mayor conocimiento de las personas afectadas con dengue, tendrán la práctica preventiva adecuada para su salud, de allí la importancia de la puesta en práctica de la prevención como actividad cotidiana, pudiendo con ello frenar y evitar la presencia de enfermedades metaxénicas como el dengue y otras.

El 95.39\% de las personas afectadas con dengue tienen conocimientos adecuados, siendo en su mayoría personas con secundaria completa, considerando con ello que el nivel educativo es una intervención importante para la población, porque mediante ello, se logrará la identificación oportuna de signos y síntomas de los distintos tipos del virus, el ciclo vital que tiene el vector trasmisor del dengue, y al mismo tiempo el reconocimiento de complicaciones que resultaría en la estancia hospitalaria de la persona.

El $89,47 \%$ de las personas afectadas con dengue, siendo en la mayoría de sexo femenino, sí practican medidas preventivas, esto puede deberse a la participación activa de ellas, en las principales actividades preventivas como son las campañas de abatización, participan y apertura en las visitas domiciliarias, uso de mosquiteros, etc.

\section{Bibliografía}

1. Organización de las naciones unidas (ONU). El dengue amenaza a la mitad de la población mundial [Internet]. Nueva York: Organización de las Naciones Unidas [Revisado 02 May 2020]. Disponible en: https://news.un.org/es/story/2019/11/14654 21

2. Organización Panamericana de la salud (OPS). Veintiún Países de Asia y las Américas comparten experiencias sobre dengue en un seminario impulsado por la OPS/OMS [Internet]. Washington: Organización Panamericana de la Salud [Revisado 28 Jun 2019]. Disponible en: https://www.paho.org/hq/index.php?option=c om_content\&view $=$ article\&id $=13064: 21$ paises-americas- $y$-asia-compartenexperiencias-dengue\&ltemid $=135 \&$ lang $=e s$

3. Ministerio de Salud (MINSA). Número de casos de dengue Perú 2018 [Internet]. Perú: Centro Nacional de Epidemiologia, Prevención y Control de Enfermedades [Revisado 15 Abr 2019]. Disponible en: http://www.dge.gob.pe/portal/docs/vigilancia /sala/2018/SE01/dengue.pdf

4. Hernández R. Metodología de la Investigación. 6. México: McGraw - Hill; 2015.601p

5. Centro para el Control y la Prevención de enfermedades. Launch Stats 2.0 en español [Internet]. Atlanta: CDC [Revisado 26 Jun 2019]. Disponible en: https://www.decisionanalyst.com/download/

6. Ministerio de Salud (MINSA). Guía de práctica clínica para la atención de casos de dengue en el Perú [Internet]. Perú: Ministerio de salud, 2017 [Revisado 13 Nov 2019]. Disponible en: https://cdn.www.gob.pe/uploads/document/fi le/289206/071-2017-MINSA.PDF

7. Mondragón M. Uso de la correlación de Spearman en un estudio de intervención [Internet]. México: Iberoamericana; 2015 [Revisado 01 Jun 2019]. Disponible en: http://dialet.unirioja.es/descarga/articulo/515 6978.pdf

8. Elio S. Manual de bioética I fundamento y ética biomédica. $5^{\circ}$ ed. Madrid; 2015

9. Díaz I, García C, León M, Ruiz F, Torres F. Guía de asociación entre variables (Pearson y Spearman en SPSS) [Internet]. Chile: Universidad de Chile; 2014 [Revisado 13 Nov 2019]. Disponible en: https://www.ucursos.cl $>$ facso $>$ material_docente $>$ bajar

10. Campos S, Corcino A. Conocimientos y prácticas en la prevención y control del dengue, en pobladores del asentamiento humano Santa Rosa Alta [Tesis de licenciatura en internet]. 
Lima: Universidad Norbert Wiener; 2017 [Revisado 14 May 2019]. 75p. Disponible en: http://repositorio.uwiener.edu.pe/bitstream/h andle/ $123456789 / 938 /$ TITULO\%20\%20Corcino\%20Navarro\%2C\%20Angella\%20Yolil .pdf? sequence $=1$ \&isAllowed $=y$

11. Núñez J. Conocimientos y actitudes frente a la enfermedad del dengue en madres de familia que asisten al Centro de salud "La tinguiña", junio de 2017. [Tesis de licenciatura en internet]. Ica: Universidad Autónoma de Ica; 2017 [Revisado 01 Mar 2020]. 35p. Disponible en:

http://repositorio.autonomadeica.edu.pe/hand le/autonomadeica/155

12. Juárez A. Nivel de conocimientos y prácticas sobre prevención de dengue en pacientes atendidos en el hospital de apoyo II - Sullana, enero 2018 [Tesis de licenciatura en internet]. Piura: Universidad Nacional de Piura; 2018 [Revisado 01 Mar 2020]. 41p. Disponible en: http://repositorio.unp.edu.pe/bitstream/handl e/UNP/1145/CIE-JUA-OLA-

18.pdf? sequence $=1$ \&isAllowed $=y$

13. Ministerio de salud (MINSA). Perú: Porcentaje de población por etapas de vida [Internet]. Perú: Ministerio de Salud; 2016 [Revisado 02 May 2020]. Disponible en: http://www.minsa.gob.pe/estadisticas/estadist icas/indicadoresSalud/demograficos/poblacion total/POBVIDMacros.asp

14. Instituto nacional de estadística e informática (INEI). Nivel de educación alcanzado por mujeres y hombres de 25 y más años de edad [Internet]. Perú: Instituto Nacional de Estadística e Informática; 2018 [Revisado 02 May 2020]. Disponible

en:

http://m.inei.gob.pe/estadisticas/indicetematico/nivel-de-educacion-alcanzado100221

15. Amador L, Monreal C, Marco M. El adulto: etapas y consideraciones para el aprendizaje. Eúphoros. 2001: p3

16. Jiménez G. Teorías del desarrollo III [Internet]. México: Red Tercer Milenio; 2012 [Revisado 02 May 2020]. Disponible en:
http://www.aliat.org.mx/BibliotecasDigitales/E ducacion/Teorias_del_desarrollo_Ill.pdf

17. Rodríguez A. Conocimientos, actitudes y prácticas sobre la prevención del dengue en los hogares de Rio seco, Sector 3 - El porvenir Trujillo [Tesis de licenciatura en internet]. Trujillo: Universidad Cesar Vallejo; 2016 [Revisado 01 Mar 2020]. 32 p. Disponible en: https://repositorio.ucv.edu.pe/bitstream/hand le/20.500.12692/778/rodriguez_ta.pdf?seque nce $=1$ \&isAllowed $=y$

18. Juárez A. Nivel de conocimientos y prácticas sobre prevención de dengue en pacientes atendidos en el hospital de apoyo II - Sullana; 2018 [Tesis de licenciatura]. Piura: Universidad Nacional de Piura; 2018 [Revisado 01 Mar 2020]. $41 \mathrm{p}$. Disponible en: http://repositorio.unp.edu.pe/bitstream/handl e/UNP/1145/CIE-JUA-OLA18.pdf? sequence $=1$ \&isAllowed $=y$

19. Quispe K, Zevallos M. Nivel de conocimiento y prácticas de medidas preventivas de dengue de los pobladores de patria, Pilcopata, Cusco 2018. [Tesis de licenciatura en internet]. Cusco: Universidad Nacional de San Antonio Abad del Cusco; 2018 [Revisado 01 Mar 2020]. 61p. Disponible en: http://repositorio.unsaac.edu.pe/bitstream/ha ndle/20.500.12918/4352/253T20190396_TC. pdf? sequence $=1$ \&isAllowed $=\mathrm{y}$

20. Jiménez I, Moya M. La cuidadora familiar: sentido de obligación naturalizado de la mujer a la hora de cuidar [Internet]. España: Enfermería Global [Revisado 02 May 2020]. Disponible

en: https://doi.org/10.6018/eglobal.17.1.292331

21. Massé C. La mujer y el cuidado de la vida. Comprensión histórica y perspectivas de futuro [Internet]. Sevilla: Cátedra de Bioética de la Universidad Pontificia Comillas: 2017 [Revisado 02 May 2020]. Disponible en: http://aebioetica.org/revistas/2017/28/94/29 1.pdf 
22. Niño B, Yong H. Conocimientos y Prácticas en prevención de dengue post fenómeno del niño costero [Tesis para optar el título de médico cirujano]. Chiclayo: Universidad Nacional Pedro Ruiz Gallo; 2018 [Revisado 02 May 2020]. 73p. Disponible

en: http://revmedtropical.sld.cu/index.php/medtr opical/article/view/410/260

23. Kozier B. Erb G. Berman A. Snyder S. Fundamentos de enfermería: Conceptos, proceso y práctica. $7^{\mathrm{a}}$. Ed. Madrid: España. Ed. McGraw - Hill: Interamericana. 2004. Vol. I Pp. $187-190 ; 418-419$

24. Oviedo G. La definición del concepto de Percepción en Psicología con Base en la Teoría Gestalt [Internet]: Brasil: Blog da Psicologia da Educação [Revisado 21 Nov 2019]. Disponible en:

https://www.ufrgs.br/psicoeduc/gestalt/perce pcion-en-la-teoria-gestalt/

25. HRA. Dengue y dengue grave. [Internet]. Chile: Ministerio de Salud [Revisado 13 Nov 2019]. Disponible en: https://www.minsal.cl/dengue/

26. NEWS. OMS. El dengue es mucho más peligroso para los humanos que el virus del zika [Internet]: Brasil: BBC Mundo; 2016 [Revisado 13 Nov 2019]. Disponible en: https://www.bbc.com/mundo/noticias/2016/0 2/160203_salud_oms_dengue_mas_peligroso_ que_zika_gl

27. Hernández A, Guillen L. Responsabilidad familiar ¿Una cuestión de género? [Internet]. Murcia: Universidad de Murcia. [Revisado 18 Jun 2021]. Disponible en: https://eduso.net/res/wpcontent/uploads/2020/06/responfa_res_21.pd $\mathrm{f}$

28. Duarte J, Baltazar J. Igualdad, Equidad de Género y Feminismo, una mirada histórica a la conquista de los derechos de las mujeres [Internet]. México: Universidad Autónoma de Nuevo León; 2015 [Revisado 18 Jun 2021]. Disponible en: https://www.redalyc.org/jatsRepo/4763/4763 50095006/html/index.html 